\title{
Appeals to Image and Claims About Quality: Understanding the Psychology of Advertising
}

\author{
Mark Snyder and Kenneth G. DeBono \\ University of Minnesota
}

\begin{abstract}
In three investigations we examined the evaluative and behavioral reactions of high and low self-monitoring individuals to two advertising strategies: appeals to a product's image and claims about a product's quality. High self-monitoring individuals reacted more favorably to image-oriented advertisements, were willing to pay more for products if they were advertised with an image orientation, and were more willing to try a product if it was marketed with an image appeal. By contrast, low self-monitoring individuals reacted more favorably to product-quality-oriented ads, were willing to pay more for products if they were advertised with a quality orientation, and were more willing to try a product if it was marketed with a quality claim. Theoretical and practical implications of these findings for advertising strategies, as well as theoretical implications of these findings for the nature of attitudes, are explored.
\end{abstract}

It has been called "the most potent influence in adapting and changing [our] habits and modes of life, affecting what we eat, what we wear, and the work and play of the whole nation" (Coolidge, cited by Fox, 1984, p. 97). It has been compared with "such long-standing institutions as the school and the church in the magnitude of its social influence" (Potter, 1954, p. 167). It "dominates the media, it has vast power in the shaping of popular standards, and it is really one of the very limited groups of institutions which exercise social control" (Potter, 1954, p. 167). "It" is advertising, whose messages reach out in words and in pictures, from newspapers and magazines, from radios and televisions.

For most people, advertising is all but impossible to avoid or to ignore. On television alone, viewers are exposed to tens of thousands of commercial messages every year (Hacker, 1984). These messages may be viewed as attempts at persuasion and social influence. Indeed, one of the giants of the advertising in-

This research and the preparation of this manuscript were supported in part by National Science Foundation Grant BNS 82-07632 to Mark Snyder. We thank Russell Nettle for his assistance in conducting the investigations, and Allen M. Omoto, Jeffry A. Simpson, and Dave Smith for their helpful comments on the manuscript.

Requests for reprints should be sent to Mark Snyder, Department of Psychology, University of Minnesota, 75 East River Road, Minneapolis, Minnesota 55455. dustry, William Bernbach of the Doyle Dayne Bernbach agency once said that "Advertising is persuasion, and persuasion is ... an art. Advertising is the art of persuasion" (cited by Fox, 1984, p. 251). As persuasion artists, the creators of advertising seem to belong to two schools, each of which has flourished throughout the history of the advertising industry. Within the trade, these two schools are known, respectively, as the "soft-sell" approach and the "hard-sell" approach (cf. Fox, 1984).

Practitioners of the soft-sell approach typically create ads that appeal to the images associated with the use of the product, images that one may gain and project by using the product. Practitioners of this image-based approach to advertising believe that how a product is packaged by its advertising is as important as the product itself. Therefore, they tend to create advertisements that are very striking in their visual appeal; they pay particular attention to the finer details of form and color. Typically, the copy associated with these ads emphasizes the image of the product or, more specifically, the images associated with the use of the product. These image-oriented ads rarely, if ever, make any explicit mention of the quality of the product, and, indeed, little emphasis is placed on the product itself.

Consider the case of the ad campaign for Arrow shirt collars, which focused not on the product itself but on the image of the man 
who used it. In this case, the advertising agency "created a campaign stressing the accessories and background of the man who wore the product. Instead of picturing the collar by itself, [they] put it around the neck of a stylish young man, impossibly clear of eye, clean of jowl and square of jaw and surrounded with opulent possessions and women" (Fox, 1984, p. 44). Or, consider the case of the DeSoto car ads, which pictured young people, happily at play, along with the simple message, "Expect to be stared at." Perhaps the best known example of image-oriented advertising is the Marlboro man, emphasizing the rugged, masculine image of the man who smokes Marlboro cigarettes. In not one of these cases does the ad contain any explicit information about the product itself, only allusions to the images to be gained by identifying oneself with the product.

By contrast, practitioners of the hard-sell approach to advertising have created rather different ads, ones that focus on claims about the intrinsic merit, inherent quality, and functional value of the product itself. Their ads tell the consumer how good the product is, how well it works, or, in the case of things to eat and drink, how good they taste. For these advertisers, it's the "matter, not the manner" that counts (Fox, 1984, p. 324). The earliest efforts of this school were on behalf of patent medicines and cure-alls, one of the very earliest of which was Lydia E. Pinkham's Vegetable Compound, advertised as "a sure cure for all female weaknesses, . . . efficacious and immediate in its effects" (cited by Fox, 1984, p. 141). Recent advertisements for Total cereal, emphasizing the nutritional benefits of the cereal, clearly fall into this category. So too do Pepsi Cola's now-famous series of Pepsi challenge taste tests, designed to communicate the supposedly superior taste quality of Pepsi and, in so doing, counter Coke's claim that "It's the real thing."

There is no doubt about it. The history of advertising testifies to the faith that these two strategies have engendered in their proponents (for a review, see Fox, 1984). Of course, some ads feature elements of both strategies, presenting information both about image and about quality. Nevertheless, the fundamental question to be asked is that of the basis of the effectiveness of either type of advertising appeal. What is it that makes image and quality appeals succeed in engaging, motivating, and persuading consumers? In other words, what are the psychological mechanisms involved that render each of these strategies successful?

One way to address a question such as this one is to identify categories of individuals who are especially responsive to either type of advertising: one category of individuals who are especially responsive to image-based advertising appeals and a contrasting category of individuals who are especially responsive to product-quality-based advertising appeals. Once identified, these categories of individuals can provide a more thorough understanding of the reasons why these two markedly different types of appeals are effective. Members of each category may serve as the ideal candidates in one's investigation of the dynamics of each strategy in operation. Moreover, susceptibility to one or other type of advertising strategy may be but one specific feature of a larger and more extensive syndrome of regular and consistent differences in how members of these categories think, feel, and act. Then the differing generalized interpersonal orientations characteristic of these contrasting categories of individuals may provide a framework within which to understand the effectiveness of advertising. (For a more elaborated discussion of this strategy of inquiry in personality and social psychology, see Snyder \& Ickes, 1985.)

Are there, then, these two categories of individuals who are differentially influenced by these two types of advertising appeals? Specifically, are there individuals who typically are particularly responsive to advertisements that stress the image associated with the use of a product and, conversely, are there individuals who typically are especially influenced by advertisements that emphasize the quality of the product? There are reasons to believe that these two contrasting categories of individuals may be identified with the psychological construct of self-monitoring (Snyder, 1974, 1979).

High self-monitoring individuals typically strive to be the type of person called for by each situation in which they find themselves (Snyder \& Monson, 1975). They are adept at tailoring their behavior to fit social and interpersonal considerations of situational appro- 
priateness (Lippa, 1976) and, as a result, their behavior often displays marked situation-tosituation shifts in the images they convey to other people (Danheizer \& Graziano, 1982; Shaffer, Smith, \& Tomarelli, 1982). These high self-monitoring individuals are identified by their relatively high scores on the Self-Monitoring Scale (Snyder, 1974).

Because of their concerns with being the right person in the right place at the right time, these high self-monitoring individuals ought to be very sensitive to the images of self that they project in social situations (indeed, there is some suggestion that they may be; Snyder, Berscheid, \& Glick, 1985), and, as such, they may be especially attentive to and influenced by advertising messages that convey information about the images that they acquire and project by virtue of using particular consumer products. In other words, to the extent that an advertisement allows high self-monitoring individuals to perceive that a given product has the potential to be used to create or enhance an image, they should react favorably to it. They should respond to the cigarette ad that promises sophistication (even if the ad says nothing about the quality of the tobacco in the cigarette), to the car ad that features a sportylooking car (even if the ad says nothing about the performance and handling characteristics of the car), and to the toothpaste ad that offers whiter teeth and brighter smiles (even if the ad says nothing about the cavity-fighting capability of the toothpaste).

By contrast, low self-monitoring individuals typically do not attempt to mold their behavior to fit situational and interpersonal considerations (Snyder \& Monson, 1975). Instead, these individuals tend to guide their behavioral choices on the basis of information from relevant inner sources, such as attitudes, feelings, and dispositions (Snyder \& Tanke, 1976). As a result, low self-monitoring individuals typically display substantial correspondence between their private attitudes and their actual behavior in social contexts (Snyder \& Swann, 1976; Zanna, Olson, \& Fazio, 1980). Low selfmonitoring individuals are identified by their relatively low scores on the Self-Monitoring Scale (Snyder, 1974).

Unlike their high self-monitoring counterparts, low self-monitoring individuals are less concerned with the images they project to others in social situations; instead, they are more concerned that their behavior in social contexts be an accurate reflection of their underlying attitudes, values, and dispositions. As such, they may be particularly responsive to advertisements that feature appeals to a product's quality. Information about product quality may be readily interpreted by these individuals in terms of their underlying attitudes, values, and other evaluative reactions. Take, for example, a low self-monitoring individual who enjoys the taste of Scotch whisky and who also drinks Scotch whisky. To maximize the consistency between this individual's favorable attitude toward Scotch and the behavior of drinking a Scotch whose taste he or she actually enjoys, as well as to maximize the consistency between this individual's behavior of drinking Scotch and the accompanying evaluative reaction, "I am enjoying the taste of this Scotch," this individual ought to drink only those brands of Scotch that taste the way good Scotch should taste, brands whose taste this individual therefore would enjoy. Hence this individual should be particularly attentive and responsive to advertisements that inform him or her about the good taste of particular brands of Scotch. Such ads would provide information useful to this individual in making consumer decisions that provide opportunities to act in a manner consistent with underlying attitudes (in this case, to drink a Scotch the taste of which he or she enjoys), as well as opportunities to maximize the consistency between the behavior of drinking Scotch and the evaluative reaction of enjoying the taste of the Scotch he or she drinks.

Are high and low self-monitoring individuals differentially responsive to ads that promise images and to appeals that feature product quality? In our research, designed to answer this question, we have created advertisements that, in pictures and words, represent imagebased and product-quality-based messages to consumers. Reactions to our ads, collected in a series of empirical investigations, suggest that high self-monitoring individuals are particularly responsive to image-oriented advertising appeals and that low self-monitoring individuals are particularly responsive to productquality advertising appeals. 


\section{Study 1}

In Study 1, we created three sets of magazine advertisements, each set containing two advertisements for a particular product. We advertised whisky, cigarettes, and coffee, three frequently advertised consumer products. The two advertisements for each product were identical in all respects except for one: the written message or slogan associated with the picture. One slogan was an appeal to the image associated with the use of the product; the other slogan was a claim about the product's quality.

\section{Method}

\section{Participants}

Fifty male and female undergraduates enrolled in introductory psychology at the University of Minnesota participated in this investigation for course credit. On the basis of a median split of their Self-Monitoring Scale scores (Snyder, 1974), obtained in an earlier questionnaire survey, we categorized half of the participants as high self-monitoring individuals and half as low self-monitoring individuals.

\section{Stimulus Materials}

We created three sets of magazine type advertisements, each set containing two advertisements for a particular product. Specifically, we advertised Canadian Club whisky, Barclay cigarettes, and Irish Mocha Mint flavored coffee, with the following contents.

Canadian Club. The picture for this set of advertisements prominently displayed a bottle of Canadian Club resting on a set of house blueprints. The written copy for the image-oriented advertisement stated, "You're not just moving in, you're moving up," and the product-qualityoriented advertisement claimed that "When it comes to great taste, everyone draws the same conclusion."

Barclay cigarettes. Here, the pictorial content depicted a handsome gentleman, about to light up a cigarette, looking into a mirror at his female companion. The woman's hand is shown resting on the gentleman's shoulder. The image-oriented message read, "Barclay . . . you can see the difference," and the product-quality-oriented message read, "Barclay . . . you can taste the difference."

Irish Mocha Mint. For this set, the picture showed a man and a woman relaxing in a candle-lit room, smiling at each other while drinking Irish Mocha Mint coffee. The image-oriented ad promised to "Make a chilly night become a cozy evening with Irish Mocha Mint," and the productquality ad informed the consumer about "Irish Mocha Mint: A delicious blend of three great flavors-coffee, chocolate, and mint."l

\section{Procedure}

When participants arrived for their individual appointments, the experimenter informed them that their task would be to help in evaluating the relative merits of advertisements currently being studied by researchers at the university. The experimenter then presented, sequentially, the three sets of advertisements (with their order of presentation counterbalanced across participants). After each set, participants filled out a 12-item questionnaire on which they were to make evaluative comparisons between the two advertisements in the set. For example, the questionnaire asked "Overall, which ad do you think is better?" "Which one appeals to you more?" "Which ad do you think would be more successful?"

\section{Results and Discussion}

We predicted that high self-monitoring individuals would react more favorably than low self-monitoring individuals to the image-oriented advertisements, but that low self-monitoring individuals would respond more favorably than high self-monitoring individuals to the product-quality-oriented advertisements. To derive an index of favorability toward the advertisements, we assigned participants a score of 1 each time that, in making evaluative comparisons between two ads, they favored the image-oriented ad, and a 0 each time they favored the product-quality-oriented ad. For each product, the 12-item index created by this scoring procedure was internally consistent (for Canadian Club, KR-20 $=.91$; for Barclay, KR-20 = .95; for Irish Mocha Mint, KR-20 = 91). Therefore, to obtain for each product an index of favorability toward each type of ad, we summed the participants' scores over the 12 items for each product. This in essence creates, for each product, a $0-12$ index of favorability toward the two types of ads; higher scores indicated greater favorability toward the image-oriented ad and lower scores indicated greater favorability toward the product quality ad. Means for this index of favorability toward each type of ad are presented, for each product, in Table 1.

\footnotetext{
'As a check on the effectiveness of the manipulation, we presented 10 judges with the three sets of advertisements and, after every set, asked them, "Which ad do you think is directed at concerns about product quality?" and "Which ad do you think is directed at concerns about product image?" All of the judges correctly classified all of the advertisements into the image-oriented and productquality-oriented categories they had been designed to represent.
} 
Table 1

Evaluations of Advertisements: Study 1

\begin{tabular}{cccc}
\hline & \multicolumn{3}{c}{ Product } \\
\cline { 2 - 4 } $\begin{array}{c}\text { Self-monitoring } \\
\text { category }\end{array}$ & $\begin{array}{c}\text { Canadian } \\
\text { Club }\end{array}$ & Barclay & $\begin{array}{c}\text { Irish Mocha } \\
\text { Mint }\end{array}$ \\
\hline High & 6.84 & 5.00 & 7.40 \\
Low & 4.88 & 3.68 & 6.08 \\
\hline
\end{tabular}

Note. Range $=0-12$. Higher scores indicate greater favorability toward image-oriented advertisements, and lower scores indicate greater favorability toward product-qualityorjented advertisements.

We then entered the participants' scores on the favorability index into an analysis of variance (ANOVA) with one between-subject factor (self-monitoring) and one within-subject factor (product). This analysis revealed a statistically significant main effect for self-monitoring propensity, $F(1,48)=4.21, p<.05$; that is, as predicted, high self-monitoring individuals reacted more favorably to the image-oriented ads than did low self-monitoring individuals, and low self-monitoring individuals reacted more favorably than did high self-monitoring individuals to the product-quality-oriented ads. Moreover, the differential favorability of high and low self-monitoring individuals toward the image and quality advertisements was evident, to some extent, for each of the three products. Tests of simple main effects (cf. Keppel, 1982) indicated that the cell means on the favorability index were in the predicted direction for the Barclay ad, the Canadian Club ad, and the Irish Mocha Mint ad: $t(48)=1.36$, $p<.10 ; t(48)=1.84, p<.05$; and $t(48)=$ $1.34, p<.10$, respectively.

Clearly, individuals high and low in selfmonitoring have different evaluative reactions to advertising that is based on appeals to image and claims about product quality. Although the effectiveness of an advertising campaign can, in part, be measured by the evaluative reactions to the advertisements, this is surely not the whole picture. The goal of any advertising strategy is not only to elicit a favorable reaction from the consumer, but also to induce the individual to purchase the particular product. Therefore, to determine how generalized these evaluative reactions to image-ori- ented and product-quality-oriented advertising are, and to examine the effects of these differential evaluations on actual consumer behavior, we next examined the impact of these two modes of advertising on one important feature of consumer behavior.

\section{Study 2}

In Study 2, we sought to determine whether the way a product is advertised would have any impact on how much consumers would be willing to pay for that product. On the basis of the results of the first study, we predicted that high self-monitoring individuals would be willing to pay more for products if they were advertised with appeals to their images than with claims about their quality. By contrast, we predicted that low self-monitoring individuals would be willing to pay more for identical products if their advertising focused on quality rather than images.

\section{Method}

\section{Participants}

Forty male and female undergraduates enrolled in introductory psychology at the University of Minnesota participated for course credit. On the basis of a median split of their Self-Monitoring Scale scores (Snyder, 1974), obtained in an earlier questionnaire survey, we categorized half of the participants as high self-monitoring individuals and half as low self-monitoring individuals.

\section{Procedure}

The experimenter informed participants, scheduled in groups of 3 to 4 and assigned randomly to one of two conditions, that as part of an ongoing research program on advertising, they would respond to a number of advertisements that presently were being pretested. The experimenter then presented participants in one condition with three image-oriented advertisements, and those in the other condition with three product-quality-oriented advertisements (which in each case were the same three ads developed for Study 1, presented sequentially in a counterbalanced order).

After viewing each ad, participants filled out a questionnaire, the critical item of which was "How much would you be willing to pay for this product?" To avoid extreme responses on this question, the experimenter gave participants ranges from which they could select their prices. The ranges provided for Canadian Club, Barclay, and Irish Mocha Mint were $\$ 5.00-15.00, \$ 0.50-1.50$, and $\$ 2.00$ 5.00 , respectively, ranges chosen so as to approximately 
represent prices at which these products could be purchased at the time of the investigation.

\section{Results and Discussion}

The mean prices participants were willing to pay for each product are presented in Table 2. To test our hypotheses about the influence of advertising, we entered participants' "willingness to pay" prices into a $2 \times 2 \times 3$ (Self-Monitoring $\times$ Type of Ad $\times$ Product) ANOVA; self-monitoring and type of ad were between-subjects factors and product was a within-subjects factor.

This overall analysis revealed a highly significant Self-Monitoring $\times$ Type of Ad interaction, $F(1,36)=23.87, p<.001$. As predicted, high self-monitoring individuals were willing to pay more for the products if they were advertised with an image orientation than if they were advertised with a quality orientation, $t(36)=1.93, p<.05$, and low self-monitoring individuals were willing to pay more for the products if they were advertised with claims about their quality than if they were advertised with appeals to their images, $t(36)=$ $2.14, p<.05$. Moreover, the absence of a significant three-way interaction, $F(2,72)<1$, suggests that there were no reversals of the trend across the three products. However, analyses of the Self-Monitoring $\times$ Type of Ad interaction for each product considered separately revealed that this effect was particularly strong for the Canadian Club ads, $F(1,106)=$ $14.92, p<.01$, less so for the Irish Mocha Mint ads, $F(1,106)=2.14, p<.15$, and even less so for the Barclay ad, $F<1, n s$, although in all three instances the means were in the predicted direction.

These results indicate that the differential favorability of high and low self-monitoring individuals to image and quality appeals is accompanied by differences in at least one relevant consumer behavior, namely, how much they would be willing to pay for products. For high self-monitoring individuals, favorable images were worth money; by contrast, for low self-monitoring individuals, quality was worth paying for. We next sought to determine whether these differing orientations toward advertising extend so far as to influence actual decisions to consume or not to consume prod-
Table 2

Price Willing to Pay: Study 2

\begin{tabular}{|c|c|c|}
\hline \multirow{2}{*}{$\begin{array}{c}\text { Type of } \\
\text { advertisement }\end{array}$} & \multicolumn{2}{|c|}{ Self-monitoring category } \\
\hline & High & Low \\
\hline \multicolumn{3}{|l|}{ Canadian Club $^{a}$} \\
\hline Image & 9.75 & 7.50 \\
\hline Quality & 8.24 & 8.64 \\
\hline \multicolumn{3}{|l|}{ Barclay ${ }^{b}$} \\
\hline Image & 0.89 & 0.74 \\
\hline Quality & 0.89 & 0.94 \\
\hline \multicolumn{3}{|c|}{ Irish Mocha Mint ${ }^{c}$} \\
\hline Image & 3.43 & 2.97 \\
\hline Quality & 3.28 & 3.50 \\
\hline
\end{tabular}

Note. Dollar signs omitted.

Range $=\$ 5.00-\$ 15.00 .{ }^{\mathrm{b}}$ Range $=\$ 0.50-\$ 1.50 .{ }^{\mathrm{c}}$ Range $=$ $\$ 2.00-\$ 5.00$.

ucts on the basis of information gleaned from their advertising.

\section{Study 3}

Are high self-monitoring individuals more willing to actually consume a product if it is advertised with an appeal to image than with a claim about product quality? And, conversely, are low self-monitoring individuals more willing to actually consume a product if it is advertised with a quality orientation than with an image orientation? To answer these questions, we conducted Study 3, in which consumers were offered the opportunity to try out a new shampoo.

\section{Method}

\section{Participants}

Forty introductory psychology undergraduates at the University of Minnesota participated in this study for course credit. On the basis of a median split of their scores on the Self-Monitoring Scale (Snyder, 1974), we categorized half of the participants as high self-monitoring individuals and half as low self-monitoring individuals.

\section{Procedure}

The experimenter, blind to the participant's self-monitoring score and posing as a market researcher, contacted participants by telephone and offered them the following opportunity to participate in a test marketing study:

$\mathrm{Hi}$, , my name is and I work for a marketing research firm here in the Twin Cities. Presently, we are surveying college students to see if, in the future, 
they would be interested in trying out a new shampoo that our client plans to market. However, before you tell me if you would be interested in trying this shampoo, let me tell you a little about it.

At this point, the experimenter delivered one of the following messages, determined by random assignment.

Image message: The results of recent laboratory tests have indicated that while compared to other shampoos, this brand usually rates about average in how it cleans your hair, it consistently rates above average in how good it makes your hair look.

Quality messuge: The results of recent laboratory tests have indicated that while compared to other shampoos, this brand usually rates about average in how good it makes your hair look, it consistently rates above average in how clean it gets your hair.

After delivering one of the two messages, the experimenter asked all of the participants the following two questions:

Now, , what I would like you to do is to indicate for me which of the following verbal descriptions best describes your willingness to use this shampoo: definitely not, probably not, unsure, probably yes, or definitely yes. Also, with $0 \%$ indicating not at all and $100 \%$ indicating definitely willing, what percentage do you think best describes your willingness to try this shampoo?

The experimenter recorded the participants' responses, answered any questions they had, and then thanked them for their time.

\section{Results and Discussion}

To create an index of willingness to use the shampoo, we coded the participants' answers to the first dependent variable in the following manner: 1 point for answering definitely not, 2 points for probably not, 3 points for unsure, 4 points for probably yes, and 5 points for definitely yes. Because the participants' responses so scored were highly correlated with their percentage estimate scores on the second dependent variable $(r=.865, p<.01)$, we decided to form a composite index of willingness to use the shampoo by summing the participants' responses over the two measures. To accomplish this, we first standardized scores on each measure and then used the sum of each participant's standardized scores as an indication of willingness to try the shampoo product. Means for this composite standardized "willingness to use" index are presented in Table 3.

We then entered the participants' scores on the composite index into a $2 \times 2$ (Self-Moni-
Table 3

Willingness to Use the Product: Study 3

\begin{tabular}{crr}
\hline \multirow{2}{*}{$\begin{array}{c}\text { Self-monitoring } \\
\text { category }\end{array}$} & \multicolumn{2}{c}{ Type of message received } \\
\cline { 2 - 3 } & lmage & Quality \\
\hline High & .7626 & -.7008 \\
Low & -.9106 & .9201 \\
\hline
\end{tabular}

Note. Higher scores indicate greater willingness to use the product.

toring $\times$ Message) ANOVA. This analysis revealed a statistically reliable interaction, $F(1$, $36)=7.18, p<.05$. Evidently, high self-monitoring individuals were more willing than low self-monitoring individuals to try the shampoo if they believed that it would leave their hair looking good, $t(36)=2.06, p<.025$, and low self-monitoring individuals were more willing than high self-monitoring individuals to try the shampoo if they believed that it would leave their hair very clean, $t(36)=1.99, p<.05$.

Clearly, then, when it came to actual choices to use or not to use this consumer product, high self-monitoring individuals invoked considerations of the images associated with a product (choosing, in this case, to use the shampoo that would make their hair look good, even if it meant that their great-looking hair would be less than perfectly clean) and low self-monitoring individuals responded to attributes of the product's quality in performing its defining function (choosing, in this case, to use the shampoo that would get their hair very clean, even if their very clean hair would have a less-than-beautiful look).

\section{General Discussion}

On the basis of the converging pattern of results of these three investigations, it seems that we have succeeded in identifying two types of advertising strategies (image and quality) and two types of individuals (those high and those low in self-monitoring) who react differentially to these two strategies. High self-monitoring individuals react favorably to imageoriented ads, they are willing to pay more money for products if they are advertised with an image orientation, and they will agree to 
try a product if it is marketed with an image appeal. By contrast, low self-monitoring individuals react favorably to product-qualityoriented ads, they are willing to pay more money for products if their advertisements stress product quality, and they will agree to try a product if an appeal is made to its quality.

How are we to understand the effectiveness of appeals to images and claims about product quality? One basis for such an understanding is provided by the generalized interpersonal orientations characteristic of high and low selfmonitoring individuals. In other words, the propensity to respond favorably, at the level of evaluative reactions and at the level of behavioral choices, to image-oriented or quality-oriented advertising appeals may be one feature of the larger syndrome of differing cognitive, motivational, and behavioral processes that guide the behavior of high and low self-monitoring individuals in social contexts (for a review of the defining and characteristic features of these generalized interpersonal orientations, see Snyder, 1979). Responding favorably to image-based advertising may be yet another manifestation of a striving to be a pragmatic creature of one's situations, to project images appropriate to one's circumstances, a striving that is particularly pronounced in high selfmonitoring individuals; thus these individuals are ideal candidates for the study of the role of appeals to images in the advertising process. Similarly, responding favorably to quality-oriented advertising may be yet another manifestation of a quest to be a principled being, one with congruence between one's actions and underlying attitudes, values, and dispositions, a quest that is especially evident in low selfmonitoring individuals; thus these individuals are ideal candidates for the study of the role of claims about quality in the advertising process.

Before considering further the implications of our findings for understanding advertising as a process of persuasion and social influence, we examine more carefully the distinction between image-oriented and quality-oriented advertising strategies. As clearly defined as the distinction may be at the level of the operations used in these investigations, some further decision rules may be necessary in order to identify the general features that define and sepa- rate the two categories of advertisements. For example, is an advertisement whose message concerns "people of good taste" or one whose message concerns "quality-conscious individuals" to be classified as an appeal to image or a claim about quality? From our perspective, if the message appeals to the image of having good taste or to the image of quality consciousness that one acquires by virtue of using the product, but at the same time the message does not claim that the product tastes good or that it has high quality, then the advertisement is an image-oriented one. As such, it ought to appeal preferentially to high self-monitoring individuals. By contrast, if the message actually makes claims about the good taste or the high quality of the product as expressions of one's intrinsic desires for things that taste good or one's inherent valuing of things high in quality, then the advertisement is a quality-oriented one. As such, its claims ought to be particularly effective with low self-monitoring individuals.

Furthermore, it is necessary to specify the conditions under which the differential reactions of individuals high and low in self-monitoring to image-oriented and quality-oriented advertising can be expected to be translated into actual consumer behaviors. Can high selfmonitoring individuals be expected to buy every product that promises an image? And can low self-monitoring individuals be expected to buy every product that possesses high quality? Clearly not. How, then, can one specify which products advertised with appeals to images will actually be used by high self-monitoring individuals and which products advertised with claims about quality will actually be used by low self-monitoring individuals?

High self-monitoring individuals typically choose the images that they project on the basis of information about the appropriateness of particular images to specific social situations and interpersonal contexts. Such situational considerations also may be relevant in their responsiveness to information provided by advertising. Thus the high self-monitoring male smoker who seeks to project an image of rugged masculinity on his weekend trips with his hunting buddies to the hunting lodge may, in addition to choosing words, deeds, and expressive mannerisms appropriate to that image, also choose, at least while on hunting trips, 
to smoke the cigarettes (and perhaps prominently display the package) whose advertising promises just such an image of rugged masculinity. As well, this individual may choose not to smoke, at least in these same circumstances, the brand whose ads appeal to an image of cultural sophistication (even though, if asked, he might grant its ads highly favorable evaluative reactions). More generally, although high self-monitoring individuals may be expected to be favorable toward advertising that appeals to images, their actual choices among products so advertised may reflect the images that they actually choose to project in their social circumstances.

In the case of low self-monitoring individuals, just as their behavior in specific social contexts is thought typically to reflect their own general attitudes and dispositions, so too ought such considerations of their own personal attributes be relevant in their responsiveness to information provided by advertising. For example, the low self-monitoring individual who enjoys the taste of gin but who does not enjoy the taste of bourbon ought to be more likely to purchase the brand of gin whose advertising conveys information about its fine gin taste than the brand of bourbon whose advertising speaks of its fine bourbon taste, even though that individual ought to be expected to regard both advertisements as particularly appealing, engaging, and effective ones. More generally, low self-monitoring individuals may be expected to be generally favorable toward advertising that makes claims about product-quality attributes, but to choose among products advertised with this orientation on the basis of the fit between these products and their own attitudes, preferences, and dispositions. They would make these choices in ways that maximize the consistency between these personal attributes and their consumer behavior.

Not only does the self-monitoring conceptual framework provide a theoretical understanding of the effectiveness of advertising, but it provides some practical hints as well. One hint is that the most potent image-oriented advertisements are those that most effectively convey the message that the images associated with using the advertised products are particularly appropriate ones to project and are images that, if conveyed, will increase the likeli- hood that one will fit into important life situations. Another hint is that the most effective quality-oriented advertisements are the ones that most successfully include the message that one will, by using the advertised products, be gaining opportunities to be true to one's own personal attitudes and important values.

Our findings and our interpretation of them also provide a new perspective on the two longstanding traditions in the advertising industry: the image-oriented soft-sell approach and the claim-oriented hard-sell approach. Indeed, it very well may be that these approaches have succeeded, survived, and flourished because each one has managed to appeal to members of one category of consumers. Imageoriented advertising campaigns that have worked may have worked because they have succeeded in engaging and motivating the image concerns of high self-monitoring consumers. Claim-oriented advertising campaigns that have succeeded may have succeeded because they have been effective in engaging and motivating the quality concerns of low selfmonitoring consumers.

Perhaps, too, advertisements that feature elements of both strategies (information about image and information about quality) may succeed because each type of information succeeds in drawing different sets of consumers; that is, the image elements of such hybrid ads may draw high self-monitoring consumers at the same time as their quality elements draw low self-monitoring consumers. However, a word of caution ought to be associated with this generalization from our findings: It is not yet known whether the relative preferences of high and low self-monitoring individuals for image-oriented and quality-oriented advertising are accompanied by an actual aversion to the other type of advertising. For example, are low self-monitoring individuals, who prefer quality-oriented messages, simply indifferent to image-oriented messages (so that a hybrid ad would appeal to them as much as a qualityonly ad) or are they perhaps actively opposed to image-oriented messages (so that a hybrid ad might appeal to them less than a qualityonly ad)? Answering this question would require comparisons of image and quality ads with "no-message" ads (ones that lack both appeals to images and claims about quality), 
although it is not clear, in the context of the design of our investigations, what operations would constitute such a "no-message" comparison condition.

Our concerns with appeals to image and claims about quality are not limited to the domain of advertising. Indeed, they ought to be considered in the context of several distinctions that have been made concerning the processes of persuasion. For one, Petty and Cacioppo (1981) introduced the distinction between the central route to persuasion, whereby persuasion is due to extensive thinking about and elaboration of the persuasive message, and the peripheral route to persuasion, whereby persuasion is mediated by nonmessage factors such as source attractiveness. In addition, Chaiken (1980) distinguished between the systematic processing of a persuasive message, whereby, as Petty and Cacioppo's central route, persuasion is dependent on extensive thinking about the content of the persuasive message, and the heuristic processing of a persuasive message, whereby agreement with the message is based on the use of simple decision rules (e.g., "Experts are usually correct").

Although the conceptual distinctions these investigators make may appear to be similar to the conceptual distinction we are advancing (e.g., one may be tempted to equate imagebased appeals with the peripheral route to persuasion or to link them to heuristic processing), we believe that the research strategies used by these investigators and our research strategy are sufficiently dissimilar to render the conceptual similarity more apparent than real. In most persuasion research in which either central versus peripheral routes or systematic versus heuristic processing is examined, the content of the persuasive message is held constant and another variable (e.g., a source factor or subject's level of involvement) is manipulated (e.g., Petty, Cacioppo, \& Goldman, 1981). By contrast, in our research, the only difference between the two advertisements for any given product was the message content; no peripheral cues were manipulated. Therefore, any differences that the image and product-quality advertisements engendered must have been due to reactions to the message content itself. From this perspective, responsiveness to imageoriented and quality-oriented messages may both represent instances of central routes to persuasion.

Whether the processing of the message content itself was systematic or heuristic, we cannot say. One could engage in either systematic or heuristic processing of either type of persuasive message. Thus, for example, in processing the quality-oriented messages of our first two studies, one could invoke the heuristic, "If it promises taste, buy it," or one could systematically assess the fit between claims about the product's taste and one's abiding preferences. And, in processing the image-oriented messages of those studies, one could use the heuristic, "If it promises image, buy it," or one could systematically evaluate the strategic utility of using the product for particular image-fashioning purposes in specific situations. We suspect, in line with our previous discussion of when evaluative reactions to advertising are translated into consumer behavior, that ultimate behavioral responsiveness to advertising is the outcome of systematic processing, both for low self-monitoring individuals (who, we have suggested, assess the fit between products and their own attitudes, preferences, and dispositions) and for high self-monitoring individuals (who, we have suggested, evaluate the potential of products to aid them in creating the images they choose to project in social circumstances).

There is, in addition to the distinctions between central and peripheral routes to persuasion and between systematic and heuristic processing, another distinction that may be relevant to understanding responsiveness to messages that make appeals to image and those that make claims about quality. Kelman (1961) posited three processes of agreement with a communication: compliance, identification, and internalization. For our purposes, the most meaningful of this trio are the processes of identification and internalization. Identification is said to occur when an individual agrees with a message because that agreement allows him or her to project a desirable image and to fit into important situations and peer groups. This agreement is considered somewhat ephemeral in that it can easily change when the image projected is no longer desirable. As such, identification processes may be involved in the preferential responsiveness of high self- 
monitoring individuals to image-based appeals. By contrast, internalization is said to occur when an individual accepts a message because the message is congruent with the individual's personal value system. Accordingly, internalization processes may be implicated in the preferential impact of quality-based advertisements on low self-monitoring individuals.

Nevertheless, the applicability of Kelman's (1961) theory to our particular investigations may be limited by the fact that his theory is concerned primarily with reactions to attributes of the source of a persuasive message (i.e., expert sources tend to produce agreement by means of internalization, attractive sources tend to produce agreement by means of identification). Yet in our investigations we focused not on the source of the message but rather on the message itself. Nevertheless, it may be that messages that are linked to sources of high credibility are particularly effective with low self-monitoring individuals and that the very same messages, when linked to sources of high personal or social attractiveness, are particuharly effective with high self-monitoring individuals.

In addition to having implications for understanding advertising strategies, our findings also may have implications for understanding the nature of attitudes themselves. Taken together, our studies provide evidence, albeit indirect, that attitudes may be serving different functions for high and low self-monitoring individuals. In our studies, high self-monitoring individuals seem to have formed more favorable attitudes toward objects that they potentially could use for the purpose of creating and displaying social images. In keeping with their pragmatic orientation toward their social worlds, high self-monitoring individuals reacted positively to objects that may have been useful to them as means for achieving the goals of presenting images appropriate to their social situations. By contrast, and in keeping with their principled orientation toward their social environs, low self-monitoring individuals in our studies reacted positively to objects and issues that allowed them the opportunity to express their underlying attitudes and values.

This possibility-that the reactions of individuals high and low in self-monitoring to advertising may reflect differing functional bases of their attitudes toward consumer products-is an intriguing one. The notions that individuals may hold similar attitudes for different reasons, and that the same attitude may serve different functions for different individuals, are the fundamental tenets of the functional theories of attitudes (e.g., Katz, 1960; Smith, Bruner, \& White, 1956). Although it may not be not possible, on the sole basis of the results of this series of investigations, to specify conclusively which of the particular functions proposed by these theories underlie either the specific domain of reactions to advertising or the general domain of social attitudes, theoretical analyses of self-monitoring (e.g., Snyder, 1979) do provide some basis for conjecture.

To the extent that the characteristic interpersonal orientation of high self-monitoring individuals is a pragmatic one of fitting themselves to their social circumstances, this characteristic interpersonal orientation may also include social attitudes that are formed on the basis of how well they serve the ends of behaving in ways appropriate to the various reference groups that form one's social circumstances. As such, the social attitudes of high self-monitoring individuals may be said, in the language of the functional theorists, to be serving a social adjustive function. By contrast, to the extent that the characteristic interpersonal orientation of low self-monitoring individuals is a principled one of choosing behaviors that accurately reflect and meaningfully communicate their own personal attributes, that interpersonal orientation may also include social attitudes formed on the basis of how well they reflect and communicate more fundamental underlying values. As such, the social attitudes of low self-monitoring individuals, once again in the language of the functional theorists, may be said to be serving a valueexpressive function.

These conjectures about the links between the psychological construct of self-monitoring and the functional bases of social attitudes may hold the potential for dealing with a problem that has long plagued the functional theorists. The Achilles' heel of the functional theories has been the lack of a way to systematically test these notions (cf. Kiesler, Collins, \& Miller, 
1969). To assess the validity of a functional theory of attitudes, one must be able to identify a priori the functions being served by a given attitude for a given individual. In the past, this has proven very difficult to do and may, in part, explain why the functional theories have been in a state of hibernation for some two decades now.

However, the results of this series of studies suggest one way of overcoming this hurdle. Just as we were able to identify categories of individuals who were especially responsive to image-oriented and quality-oriented advertising messages, so too may it be possible to identify categories of individuals who are especially likely to hold attitudes serving particular types of functions. Thus, for example, if one were seeking candidates for the study of the social adjustive function of attitudes, one might seek out members of the category of high self-monitoring individuals. Similarly, if one wished to probe the dynamics of the value-expressive function of attitudes, one might focus one's efforts on members of the category of low selfmonitoring individuals. In either case, the identification and investigation of these categories of individuals would serve not as ends unto themselves but as vehicles for understanding the functional underpinnings of attitudes. The application of this hybrid "personality-social psychology" strategy to the study of attitudes very well may have the potential to awaken the functional theories of attitudes, persuasion, and social influence from their long winter of hibernation.

\section{References}

Chaiken, S. (1980). Heuristic versus systematic information processing and the use of source versus message cues in persuasion. Joumal of Personality and Social Psychology, 39, 752-766.

Danheiser, P. R., \& Graziano, W. G. (1982). Self-monitoring and cooperation as a self-presentational strategy. Journal of Personality and Social Psychology, 42, 497505 .

Fox, S. (1984). The mirror makers. New York: Morrow.

Hacker, A. (1984, June 24). Poets of packaging, sculptors of desire. New York Times Book Review, p. 1.
Katz, D. (1960). The functional approach to the study of attitudes. Public Opinion Quarterly, 24, 163-204.

Kelman, H. C. (1961). Processes of opinion change. Public Opinion Quarterly, 25, 57-78.

Keppel, G. (1982). Design and analysis: $A$ researcher's handbook (2nd ed.). Englewood Cliffs, NJ: Prentice-Hall.

Kiesler, C. A., Collins, B. E., \& Miller, N. (1969). Attitude change: A critical analysis of theoretical approaches. New York: Wiley.

Lippa, R. (1976). Expressive control and the leakage of dispositional introversion-extraversion during roleplayed teaching. Journal of Personality, 44, 541-559.

Petty, R. E., \& Cacioppo, J. T. (1981). Attitudes and perstuasion: Classic and contemporary approaches. Dubuque, IA: Wm. C. Brown.

Petty, R. E., Cacioppo, J. T., \& Goldman, R. (1981). Personal involvement as a determinant of argument-based persuasion. Journal of Personality and Social Psychology, 41, 847-855.

Potter, D. M. (1954). People of plenty: Economic abundance and the American character. Chicago: University of Chicago Press.

Shaffer, D. R., Smith, J. R., \& Tomarelli, M. (1982). Selfmonitoring as a determinant of self-disclosure reciprocity during the acquaintance process. Journal of Personality and Social Psychology, 43, 163-175.

Smith, M. B., Bruner, J. S., \& White, R. W. (1956). Opinions and personality. New York: Wiley.

Snyder, M. (1974). The self-monitoring of expressive behavior. Journal of Personality and Social Psychology. 30 , 526-537.

Snyder, M. (1979). Self-monitoring processes. In L. Berkowitz (Ed.), Advances in experimental social psychology (Vol. 12, pp. 85-128). New York: Academic Press.

Snyder, M., Berscheid, E., \& Glick, P. (1985). Focusing on the exterior and the interior: Two investigations of the initiation of personal relationships. Journal of Personality and Social Psychology, 48, 1427-1439.

Snyder, M., \& Ickes, W. (1985). Personality and social behavior. In G. Lindzey \& E. Aronson (Eds.), Handbook of social psychology (3rd ed., pp. 883-948). New York: Random House.

Snyder, M., \& Monson, T. C. (1975). Persons, situations, and the control of social behavior. Journal of Personality and Social Psychology, 32, 617-644.

Snyder, M., \& Swann, W. B., Jr. (1976). When actions reflect attitudes: The politics of impression management. Journal of Personality and Social Psychology, 34, 1034-1042.

Snyder, M., \& Tanke, E. D. (1976). Behavior and attitude: Some people are more consistent than others. Journal of Personality, 44, 510-517.

Zanna, M. P., Olson, J. M., \& Fazio, R. H. (1980). Attitudebehavior consistency: An individual difference approach. Journal of Personality and Social Psychology. 38, 432440 .

Received September 25, 1984 Revision received March 25, 1985 